\title{
Cytokinetic parameters of erythropoiesis under normal health conditions and during the development of acute lymphoblastic and acute myeloblastic leukemia
}

\author{
Evgeniy Seliverstov ${ }^{1 *}$, and Marina Skorkina ${ }^{2}$ \\ ${ }^{1}$ Department of Biology, Belgorod State National Research University, Belgorod, Russia \\ ${ }^{2}$ Department of Biochemistry, Institute of Medicine, Belgorod State National Research University, Belgorod, Russia
}

\begin{abstract}
The article presents the application of the method for determining the quantitative parameters of erythropoiesis to patients with acute leukemia. The objective of the work is an investigation of erythropoiesis cytokinetic parameters under the normal health conditions and during the development of the acute lymphoblastic leukemia and the acute myeloblastic leukemia. It was found that the distribution of reticulocytes shifts towards an increase of immature reticulocyte fraction while the ratio between maturing and immature cells remains unchanged. The method presented can be used in clinical diagnostic and scientific research of bone marrow hematopoietic activity.
\end{abstract}

\section{Introduction}

In 1982, in the framework of the USSR space programs and the study of USSR cosmonauts health after being in space, Ilyukhin et al. were improved the method for determining the quantitative parameters of erythropoiesis based on the reticulocyte number count. After comparing with the data of erythrocyte isotope labeling they confirmed the method reliability and recommended it for use in clinical diagnostic and scientific research in cases where the use of direct methods for the study of cytokinetic parameters is not possible [1].

Reticulocyte counts can provide useful information about bone marrow erythropoietic activity, the rate of reticulocyte delivery from the bone marrow into peripheral blood, and the rate of reticulocyte maturation. These parameters can be really important to studying the compensatory-adaptive reactions accompanying the development of malignant proliferation in the blood system such as leukemia and to the prediction of hemopoietic recovery in patients $[2,3]$.

However, there is a probability to determine erroneously elevated immature reticulocyte fraction (IRF) in leukemic patients by automated reticulocyte analysis which means that hematologists should examine reticulocyte distribution carefully and don't neglect the old methods such as using blood smears [4].

\section{Experimental}

The work has been performed on the base of the Department of Biology of Belgorod State National Research University in Belgorod, Russia. In the experimental part of the work venous blood of patients with acute lymphoblastic leukemia (ALL) (41 samples), and patients with acute myeloblastic leukemia (AML) (18 samples), who were undergoing medical treatment in the hematological department of the regional clinical hospital of Belgorod were used.

The control studies were performed on the blood of healthy people ( $\mathrm{n}=50,26$ women and 24 men) of mature age (25-45 years) who underwent a clinical examination in the regional clinical hospital of Belgorod. Blood sampling was performed by venipuncture by specialized medical staff. Blood was collected in Vacuette K3E vacuum tubes containing dry EDTA K 3 at a concentration of $2.0 \mathrm{mg}(0.006843 \mathrm{~mol} / \mathrm{L})$ per $1 \mathrm{~mL}$ of blood.

The study was approved by the local Ethical Committee of the Medical Institute of Belgorod State University and informed consent of all subjects was obtained according to the recommendations of the Helsinki Declaration (The International Response to Helsinki VI, The WMA's Declaration of Helsinki on Ethical Principles for Medical Research Involving Human Subjects, as adopted by the 52nd WMA General Assembly, Edinburg, October 2000).

Cytokinetic parameters of erythropoiesis were calculated by using the number of reticulocytes in unincubated and incubated blood [1]. Reticulocytes were stained by $0.1 \%$ solution of brilliant cresyl blue prepared in $0.9 \% \mathrm{NaCl}$ solution.

The blood smear was made of the unincubated blood mixed with the dye in a 1:1 ratio by volume and left at room temperature for 40 minutes. Also, another blood smear was made of the blood sample $(100 \mu \mathrm{l})$ placed in a thermostat at $37^{\circ} \mathrm{C}$ for 4 hours and then stained by brilliant cresyl blue.

\footnotetext{
*Corresponding author: seliverstov.evgeniy.s@gmail.com
} 
The number of erythrocytes per $1 \mu$ of blood was counted by using a hemocytometer.

By using an Axiostar plus microscope (Carl Zeiss, 2010), the number of reticulocytes in unincubated and incubated for 4 hours of blood samples per 1000 erythrocytes was counted. The calculation was carried out by using an oil immersion lens (magnification 100x).

Based on the Heilmeyer [5], all groups of reticulocytes were counted. Group I: cells with a densely clumped reticulum, group II: cells with an extended network of loose reticulum, group III: cells with scattered granules with residual reticulum network, group IV: cells with grain as individual strands or scattered granules (Fig. 1).

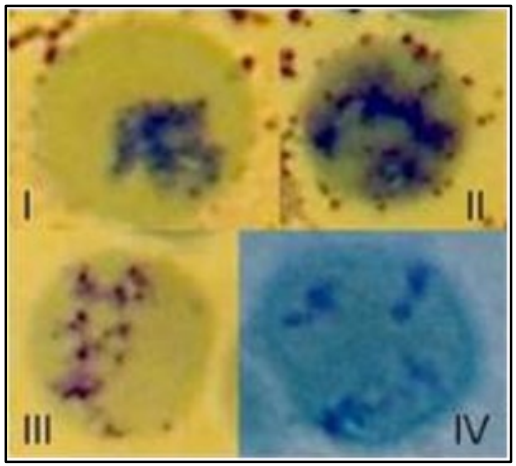

Fig. 1. Reticulocyte maturation groups (photos were taken by the authors).

According to formulas, the half-life (the period for which half of the reticulocytes mature into the erythrocytes) of reticulocytes $\mathrm{T}_{1 / 2 \mathrm{r}}$ (Fig. 2), the half-life (the period for which half of the erythrocytes are destroyed due to their senescence) of erythrocytes $T_{1 / 2 \mathrm{er}}$ (Fig. 3) and the value of the erythrocyte daily production per $1 \mu$ of blood $\mathrm{P}_{\mathrm{er}} /$ day (Fig. 4) were calculated:

$$
\lg \frac{N_{r 4}}{N_{r 0}}=-\frac{0,3010}{T_{1 / 2 r}} \times t
$$

\section{Fig. 2. Half-life of reticulocytes.}

Where $\mathrm{N}_{\mathrm{r} 0}$ - the number of all reticulocytes per 1000 erythrocytes before incubation, cells; $\mathrm{N}_{\mathrm{r} 4}$ - the number of all reticulocytes per 1000 erythrocytes after 4 hours incubation, cells; $\mathrm{t}$ - incubation time (4 hours); $\mathrm{T}_{1 / 2 \mathrm{r}}-$ the half-life of reticulocytes, hours.

$$
T_{1 / 2 e r}=\frac{T_{1 / 2 r} \times 1000}{N_{r 0} \times 24}
$$

Fig. 3. Half-life of erythrocytes.

Where $T_{1 / 2 \mathrm{er}}-$ the half-life of erythrocytes, days.

$$
P_{\text {er } / \text { day }}=\frac{0,693}{T_{1 / 2 e r}} \times N_{\text {er }}
$$

Fig. 4. Value of the erythrocyte daily production per $1 \mu l$ of blood.

Where $\mathrm{P}_{\mathrm{er} / \mathrm{day}}-\mathrm{a}$ value of the erythrocyte daily production per $1 \mu \mathrm{l}$ of blood, thousands / ( $\mu \mathrm{l} \mathrm{x}$ days), $\mathrm{N}_{\mathrm{er}}$ - the number of erythrocytes in $1 \mu \mathrm{l}$ of blood, millions / $\mu$ l.
Using the modified Kolmogorov-Smirnov test the hypothesis about the uniform distribution of empirical data was tested. The significance of differences between control and experimental samples was determined using the Mann-Whitney U-test $(\mathrm{p}<0.05)$. All data are represented by the mean values with their standard errors.

We did not have an access to the information about sex and age of patients with ALL and AML due to patient confidentiality which did not allow an adequate comparison in the sex and age groups. Therefore, the mean value for all samples was taken as a control and experimental data.

\section{Results and discussion}

Reticulocytes of I and II maturity groups were very rare and were represented by single cells in blood smears from healthy donor samples. The number of group III reticulocytes in the group of healthy donors was $3.11 \pm$ 0.37 cells per 1000 erythrocytes. For group IV reticulocytes this number was $13.60 \pm 1.20$ cells per 1000 erythrocytes.

The cytokinetic parameters of the erythropoiesis between men and women didn't differ significantly under conditions of blood system physiological regeneration.

In $46.1 \%$ of the blood samples of patients with ALL and $50 \%$ of the blood samples of patients with AML, reticulocytes were not detected, or they were represented by extremely rare single cells thus did not allow to calculate cytokinetic parameters in these samples.

Between the control (healthy people) and the experimental (patients with ALL and AML) groups, significant differences in most of the values of cytokinetic parameters were not identified. Nevertheless, there was a general increase tendency in parameters, except the halflife of erythrocytes in the group of patients with ALL, maturing/immature cells ratio $(\mathrm{Nr} 4 / \mathrm{Nr} 0)$, and number of erythrocytes per $1 \mu \mathrm{l}$ of blood (tab. 1).

There was an increase in the number of immature group I reticulocytes by $2033.3 \%(\mathrm{p}<0.05)$, group II reticulocytes by $1768.7 \% \quad(\mathrm{p}<0.05)$ and group III reticulocytes by $216.7 \%(\mathrm{p}<0.05)$ in the rest $53.9 \%$ of patients with ALL (Fig. 5).

Also, there was an increase in the number of immature group I reticulocytes by $5933.3 \%(\mathrm{p}<0.05)$ and group II reticulocytes by $1875 \%(\mathrm{p}<0.05)$ in the rest $50 \%$ of patients with AML (Fig. 6).

Also, there were two cases of ALL which we did not count in final results due to their significantly big difference in ratio between reticulocyte number before and after incubation compared to others (tab. 2).

According to the literature data, the immature data, the immature reticulocyte fraction (IRF) may be termed as the red cell equivalent of the "left shift" typically associated with neutrophilic white cells [2]. The IRF recovery in patients with acute leukemia after chemotherapy showing bone marrow hematopoietic recovery earlier than absolute neutrophil count [3].

Thus, a favorable prognosis of hematopoietic recovery for patients who showed an increased number of immature reticulocyte fraction can be expected. 
Table 1. Cytokinetic parameters of ALL and AML patients.

\begin{tabular}{|c|c|c|c|}
\hline Parameter & Donors & ALL & AML \\
\hline $\mathrm{N}_{\mathrm{er}}$, millions/ $\mu \mathrm{l}$ & $3.75 \pm 0.08$ & $4.07 \pm 0.27$ & $3.70 \pm 0.55$ \\
\hline $\mathrm{Nr}_{0}$, cells/1000 erythrocytes & $16.88 \pm 1.37$ & $22.19 \pm 3.85$ & $27.44 \pm 11.02$ \\
\hline $\mathrm{Nr}_{4}$, cells/1000 erythrocytes & $9.92 \pm 0.97$ & $14.62 \pm 3.11$ & $16.56 \pm 5.20$ \\
\hline $\mathrm{Nr}_{4} / \mathrm{Nr}_{0}$ & $0.60 \pm 0.03$ & $0.59 \pm 0.05$ & $0.67 \pm 0.07$ \\
\hline $\mathrm{T}_{1 / 2 \mathrm{r}, \text { hours }}$ & $7.83 \pm 0.99$ & $9.64 \pm 2.38$ & $41.64 \pm 3.32$ \\
\hline $\mathrm{T}_{1 / 2 \mathrm{er}}$, days & $23.86 \pm 3.51$ & $23.81 \pm 6.36$ & $236.72 \pm 127.42$ \\
\hline $\mathrm{P}_{\text {er/day }}$, thousands/ $\mu$ l x days $)$ & $202.19 \pm 20.45$ & $237.15 \pm 35.46$ & $3.56 \pm 2.47^{*}$ \\
\hline Group I reticulocytes, cells/1000 erythrocytes & $0.06 \pm 0.03$ & $1.22 \pm 0.64^{*}$ & $3.00 \pm 1.35^{*}$ \\
\hline Group II reticulocytes, cells/1000 erythrocytes & $0.16 \pm 0.07$ & $2.83 \pm 0.92^{*}$ & $6.67 \pm 3.74$ \\
\hline Group III reticulocytes, cells/1000 erythrocytes & $3.11 \pm 0.37$ & $6.74 \pm 1.44^{*}$ & $14.22 \pm 3.98$ \\
\hline Group IV reticulocytes, cells/1000 erythrocytes & $13.60 \pm 1.20$ & $15.04 \pm 2.18$ & \\
\hline
\end{tabular}

$* \mathrm{p}<0.05$

Table 2. ALL data outliers

\begin{tabular}{|c|c|c|}
\hline Parameter & ALL case № 1 & ALL case № 2 \\
\hline $\mathrm{N}_{\mathrm{er}}$, millions $/ \mu \mathrm{l}$ & 4.59 & 5.02 \\
\hline $\mathrm{N}_{\mathrm{r} 0}$, cells/1000 erythrocytes & 67 & 68 \\
\hline $\mathrm{N}_{\mathrm{r} 4}$, cells/1000 erythrocytes & 1 & 2 \\
\hline $\mathrm{N}_{\mathrm{r} 4} / \mathrm{N}_{\mathrm{r} 0}$ & 0.01 & 0.03 \\
\hline $\mathrm{T}_{1 / 2 \mathrm{r}}$, hours & 0.66 & 0.79 \\
\hline $\mathrm{T}_{1 / 2 \mathrm{er}}$, days & 0.41 & 0.48 \\
\hline $\mathrm{P}_{\text {er/day, }}$ thousands/ $(\mu \mathrm{l} \mathrm{x}$ days $)$ & 7758.2 & 7247.6 \\
\hline Group I reticulocytes, cells/1000 erythrocytes & 14 & 0 \\
\hline Group II reticulocytes, cells/1000 erythrocytes & 7 & 20 \\
\hline Group III reticulocytes, cells/1000 erythrocytes & 11 & 15 \\
\hline Group IV reticulocytes, cells/1000 erythrocytes & 25 & 36 \\
\hline
\end{tabular}

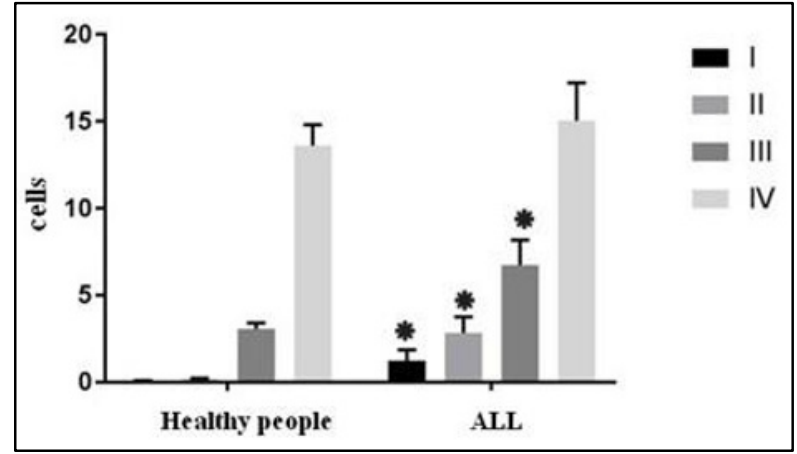

Fig. 5. The number of different reticulocyte groups in ALL blood samples.

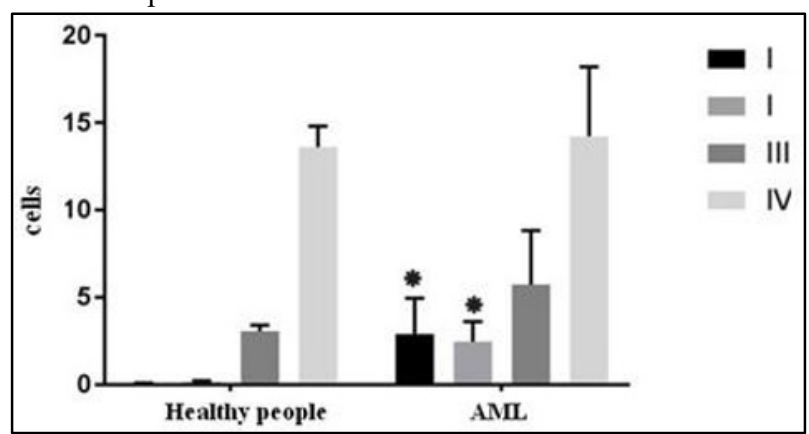

Fig. 6. The number of different reticulocyte groups in AML blood samples.

\section{Conclusion}

It was found that about half of the cases of ALL and AML were characterized by ineffective erythropoiesis when erythroid progenitors were destroyed in the bone marrow. In the rest of the cases, the regulation of erythropoiesis was rearranged by increasing the number of groups I and II immature reticulocytes. About $5 \%$ of ALL cases were characterized by accelerated processes of immature red blood cell maturation, erythrocyte destruction, and erythrocyte daily production.

However, the ratio between maturing cells and immature ones from the bone marrow remained the same as in the normal health conditions.

The formulas used for erythropoiesis cytokinetic parameter calculations can be used in clinical diagnostic and scientific research of bone marrow hematopoietic activity.

\section{References}

1. A.V. Ilyuhin, T.E. Burkovskaya, A.V. Shafirkin, N.V. Klyuchanskaya, Kosmicheskaja biologija i aviakosmicheskaja medicina. 16, 86 (1982) 
2. R.Z. Raja-Sabudin, A. Othman, K.A. AhmedMohamed, A. Ithnin, H. Alauddin, H. Alias, Z. Abdul-Latif, S. Das, F.S. Abdul-Wahid, N.H. Hussin, Saudi. Med. J. 35, 346 (2014)

3. S.E. Rauf, S.A. Khan, N. Ali, N.K. Afridi, M. Haroon, A. Arslan, Turk. J. Haematol. 33, 131 (2016)
4. J. Huh, H. Moon, W. Chung, Ann. Hematol. 86, 759 (2007)

5. L. Heilmeyer, J. Clin. Med. 121, 361 (1932) 